\title{
Narp Deletion Blocks Extinction of Morphine Place Preference Conditioning
}

\author{
Hans S Crombag*,', Mercy Dickson², Megan Dinenna', Alexander W Johnson', Mark S Perin ${ }^{3}$, \\ Peter C Holland ${ }^{1,2}$, Jay M Baraban ${ }^{2,4}$ and Irving M Reti ${ }^{2,4}$ \\ 'Department of Psychological and Brain Sciences, Neurogenetics and Behavior Center, The Johns Hopkins University, Baltimore, MD, USA; \\ ${ }^{2}$ Solomon H Snyder Department of Neuroscience, The Johns Hopkins University, Baltimore, MD, USA; ${ }^{3}$ Department of Neuroscience, Cleveland \\ Clinic Foundation, Cleveland, OH, USA; ${ }^{4}$ Department of Psychiatry and Behavioral Sciences, The Johns Hopkins University, Baltimore, MD, USA
}

\begin{abstract}
As drug abuse can be viewed as a maladaptive form of neuronal plasticity, attention has focused on defining the synaptic plasticity mechanisms that mediate the long-term effects of these drugs. As Narp is secreted at synaptic sites and binds to the extracellular surface of AMPA receptors, it has been implicated in mediating enduring forms of synaptic plasticity. Accordingly, to assess its potential role in the long-lasting behavioral effects of drugs of abuse, we have investigated the impact of Narp deletion on sustained behavioral responses elicited by repeated morphine administration. Narp knockout mice display normal locomotor sensitization and conditioned place preference, but are markedly resistant to extinction of place preference. Thus, these findings indicate that Narp plays a selective role in extinction, possibly by its effects on AMPA receptor trafficking.

Neuropsychopharmacology (2009) 34, 857-866; doi: I0.1038/npp.2008.80; published online 4 June 2008
\end{abstract}

Keywords: neuronal activity-regulated pentraxin; place preference conditioning; psychomotor sensitization; orexin; glutamate; knockout mice

\section{INTRODUCTION}

As long-lasting behavioral alterations induced by drugs of abuse can be viewed as a form of memory, there has been considerable interest in the proposal that similar molecular mechanisms may be involved in generating enduring forms of synaptic plasticity and persistent behavioral effects induced by drugs of abuse (Kalivas and O'Brien, 2008). Although the effects of cocaine on synaptic plasticity have been studied more extensively, multiple studies, conducted in rats, indicate that morphine acts in a similar fashion. For example, a single dose of morphine increases synaptic strength at excitatory synapses in the ventral tegmental area (VTA; Saal et al, 2003) and produces a delayed increase in glutamate receptor responses in the nucleus accumbens (NAc; Jacobs et al, 2005). Furthermore, repeated morphine administration induces structural changes in dendritic processes in NAc and prefrontal cortex (PFC; Robinson and Kolb, 1999), as well as changes in the level of expression and subcellular localization of GluR1 receptors (Fitzgerald et al, 1996; Glass et al, 2005, 2008).

\footnotetext{
*Correspondence: Dr HS Crombag, Behavioral and Clinical Neuroscience Research Group, University of Sussex, 5 d9 John Maynard Smith Building, Brighton, East Sussex BNI 9QH, UK, Tel: + 44410955 2500, Fax: + 44 410 614 6249, E-mail: h.crombag@sussex.ac.uk Received 15 February 2008; revised 8 April 2008; accepted 29 April 2008
}

Evidence linking neuronal immediate-early genes (IEGs) to enduring forms of neuronal plasticity has heightened interest in their role in mediating behavioral alterations induced by drugs of abuse (Nestler, 2001; Szumlinski et al, 2006). As these genes are rapidly induced by neuronal stimulation, they represent a mechanism by which drug administration could elicit long-term adaptations in neuronal function that underlie their reinforcing properties. Narp is a neuronal IEG that seems particularly well suited for mediating drug-induced plasticity because Narp encodes a secreted protein that is released at synaptic sites and binds to the extracellular surface of AMPA receptors (O'Brien et al, 1999). Although the precise effect of Narp on AMPA receptor trafficking or clustering under physiological conditions remains to be determined, recent studies indicate that deletion of all three neuronal pentraxins, Narp, NP1, and NPR, or of NPR alone, blocks LTD induced by metabotropic glutamate receptor stimulation (Cho et al, 2008). Furthermore, even though Narp knockout (KO) mice perform normally on a variety of learning tasks, they are deficient in reward devaluation learning (Johnson et al, 2007). In addition, Narp expression is enriched in several limbic system areas, including the amygdala (Reti and Baraban, 2003), PFC (Lu et al, 2002), and orexin neurons of the hypothalamus (Reti et al, 2002a) that have been implicated in mediating drug-induced behaviors (Hyman et al, 2006; Carr and Kalivas, 2006). Accordingly, to investigate the role of Narp in drug abuse, we have, in this study, assessed the 
performance of Narp KO mice in two behaviors induced by morphine: locomotor sensitization and conditioned place preference. We have found that acquisition of both these behaviors is normal in Narp KO mice. However, extinction from conditioned place preference is markedly deficient in these mice.

\section{MATERIALS AND METHODS}

\section{Subjects}

Generation of Narp KO mice has been described previously in Bjartmar et al (2006). Narp KO and WT control mice were obtained by breeding Narp heterozygotes that had been backcrossed 12 times to the C57BL/6 strain. Both male and female WT and KO mice were used. Mice were aged 12-16 weeks and weighed 19-30 g at the start of experiments. Mice were housed in a climate-controlled housing colony on a $12 \mathrm{~h}$ light/dark cycle and they had ad libitum access to food and water. All procedures were approved by the Johns Hopkins University, Institutional Animal Care and Use Committee and were in accordance with guidelines set forth by the NIH.

\section{Apparatus}

For the sensitization experiment (Experiment 1), commercially obtained activity monitors $(49 \mathrm{~cm} \quad W \times 53 \mathrm{~cm}$ $D \times 9 \mathrm{~cm} H$; Accuscan Instruments, Columbus, $\mathrm{OH})$ were used that were divided into four quadrants, yielding two activity arenas, measuring $24 \mathrm{~cm} W \times 26 \mathrm{~cm} \mathrm{D} \times 9 \mathrm{~cm} \mathrm{H}$, per monitor. Each arena was outfitted with eight sets of infrared photocell beams along the $x$ and $y$ axes that monitored horizontal activity (consecutive infrared beam breaks) using a PC-based (Versamax) software package. Each chamber was located in custom-built sound-attenuating chambers (specifications are available at http://www.nbc.jhu.edu) outfitted with an $8 \mathrm{~W}$ incandescent red-light bulb and a fan that provided continuous ventilation. The activity chambers were cleaned prior to each session using a $70 \%$ ethanol solution.

The conditioned cue preference apparatus (Experiment 2) was custom-built based on previous designs by Cunningham and colleagues $(1992,1995)$ and Vezina and Stewart (1987). Briefly, each place conditioning apparatus consisted of an open field enclosed in a separate light- and soundattenuating chamber (Med Associates, St Albans, VT). A low-level red light and constant ventilation were provided to each sound-attenuating chamber. General activity and location in the open field were monitored using eight pairs of infrared photocells, positioned along the long axis of the chamber, with a Med-PC software package (Med Associates). The floor of the open field consisted of two interchangeable halves made of one of two textures: either a 'grid' made from stainless-steel rods $(2.3 \mathrm{~mm}$ stainless-steel rods mounted $6.4 \mathrm{~mm}$ apart) or 'hole' floor (16-gauge stainless steel perforated with 6.4 -mm diameter holes). This combination of floor textures was selected on the basis of unpublished pilot studies using commercially acquired C57BL/6 mice and studies by others (Cunningham et al, 1992; Cunningham, 1995) showing that mice spend an average of about $50 \%$ time on each floor type during (preconditioning) bias/preference tests. Thus, the apparatus allowed for an 'unbiased' place preference procedure to be used (see 'Results'). Prior to each session the open field and floors were cleaned using a 70\% ethanol solution.

\section{Procedures}

Experiment 1: morphine psychomotor sensitization. To assess the function of Narp in the long-term behavioral effects of repeated morphine exposure, Narp WT and KO mice underwent a standard sensitization protocol consisting of the following phases:

Pretreatment phase (seven sessions): WT and KO mice received either repeated injections of morphine $(10 \mathrm{mg} / \mathrm{kg}$ per injection) or saline vehicle during this phase. Thus, there were four groups: two groups of Narp WT mice that received either saline $(N=9)$ or morphine $(N=9)$ each session and two groups of Narp KO mice that received either saline $(N=11)$ or morphine $(N=10)$. Each day, mice were weighed, transported to a testing room, and placed in activity monitors for a $30-\mathrm{min}$ period. This habituation period was intended to reduce the amount of spontaneous (novelty-induced) activity prior to the injection. At the end of the habituation period, the mice were removed from the activity monitor, given an intraperitoneal (i.p.) injection of morphine or saline, and placed back into the chamber for $120 \mathrm{~min}$. At the end of the 120 -min postinjection period, mice were removed and returned to the mouse colony. Thus, each session lasted a total of two and a half hours, consisting of a $30-$ min preinjection (habituation) period and a 120-min postinjection period. All groups received one session per day for a total of seven consecutive pretreatment days.

Withdrawal (7 days): Following the pretreatment phase, all the mice were left undisturbed in the housing colony for a period of 7 days.

Challenge tests (four sessions): The challenge tests were conducted during a 4-day period during which mice received one test session per day. On the first test session, all mice received an injection of saline and on the subsequent three sessions mice received an injection of morphine at a dose of 3,10 , and $30 \mathrm{mg} / \mathrm{kg}$, given in consecutive order. This way, across the 4 test days, a within-subject dose-effect curve was determined across four doses of morphine for all four groups. This within-subjects (nonrandomized) escalating dose-effect procedure was used to minimize the number of groups needed to construct a dose-effect curve across four doses of morphine, while reducing the likelihood of carryover effects across doses (eg due to development of sensitization by morphine challenge injections). On all challenge sessions, mice were placed in the activity monitors for a 1-h habituation period followed by a 3-h postinjection period.

Long-term expression of sensitization (1 day): Following a 1-month withdrawal period, during which mice remained in the animal colony, a single test was conducted during which saline or morphine pretreated WT or KO mice received a single challenge injection of morphine $10 \mathrm{mg} / \mathrm{kg}$. 
Experiment 2: morphine place conditioning. To assess the function of Narp in the development and expression of morphine place preference, WT $(N=16)$ and KO $(N=16)$ mice underwent a standard place conditioning protocol consisting of the following phases: habituation, a preconditioned test, conditioning, a postconditioning test, and an extinction phase. Sessions were conducted 5 days per week between 1100 and 1600 hours. Each session, mice were brought from the housing colony to the testing room, weighed, injected, and placed in the apparatus. At the end of each session mice were immediately removed from the apparatus and returned to the housing colony.

Habituation phase (two sessions): On two separate 30-min sessions (two sessions per day) mice received an injection of saline, were placed in the apparatus, and allowed to freely explore the entire arena. The floor of the apparatus during these habituation sessions was distinct from the ones used in the subsequent phases (see below) and consisted of a flat plastic floor.

Preconditioning test (one session): A single 30-min preconditioning test session was then conducted to determine the initial (unconditioned) preference for the two floor types. All mice received a saline injection prior to being placed into the apparatus with half the grid floor and half the hole floor. The side of the chamber (left or right) that contained each floor type was counterbalanced within genotype groups. The time spent on each floor type was recorded.

Conditioning (eight sessions): On the basis of preconditioning preference scores (ie, time spent on each floor type), mice within each genotype group were assigned to receive morphine paired with placement on either the grid or hole floor such that the average preconditioning preference for each genotype on the morphine and saline floors approximated $50 \%$. Thus, although some mice, based on the preconditioning bias, received morphine on their 'preferred' floor, other mice received morphine on the 'nonpreferred' floor, such that the average group preference for the (wouldbe) morphine- and saline-paired floors was $\sim 50 \%$. Specifically, the percent time spent on the morphine-paired $(\mathrm{CS}+)$ floor was $50.1 \pm 3.3$ and $51.96 \pm 3.5 \mathrm{~s}$ for WT and KO mice, respectively. Notably, comparison of the preconditioning preference scores of WT and Narp KO mice revealed a small preference in Narp KO mice for one floor type over the other (time spent on hole floor: $911.8 \pm 55.8$ vs 1055.6 \pm $51.1 \mathrm{~s}$ for WT and KO, respectively; Supplementary Figure 1) that did not reach significance (unpaired $t$-test, $t=1.9$, d.f. $=30, p=0.07)$.

On conditioning days, Narp WT and KO mice received an injection of saline paired with placement on one floor type (the $\mathrm{CS}-$ floor) or morphine $(10 \mathrm{mg} / \mathrm{kg}$, i.p.) paired with placement on the alternate floor type (the CS + floor). For each mouse, saline and morphine injections were administered on alternating days for a total of four injections of morphine and saline (and therefore a total of eight consecutive conditioning sessions). Immediately following each injection, the mouse was placed in the middle of the apparatus containing one of the floor textures, left for $30 \mathrm{~min}$, and then returned to the animal colony. The apparatus was cleaned with $70 \%$ ethanol between each session. Activity during the conditioning session was recorded (not presented).

Postconditioning bias test (one session): At 2 days following the final conditioning session, a single 30-min test session was conducted to assess the development of a postconditioning bias using the identical procedures as during the preconditioning bias test described above. Briefly, mice were injected with saline and placed in the middle of the apparatus containing one half of the hole floor and one half of the grid floor. The amount of time (in seconds) spent on the previously morphine- $v s$ saline-paired floor was recorded and the results were compared with those from the preconditioning bias test (see 'Results').

Extinction (23 sessions): Following the first postconditioning bias test, repeated test sessions were conducted using the same procedure to determine whether Narp deletion affects the maintenance/extinction of morphineconditioned preferences. These sessions used the same procedures as during the postconditioning bias test, consisting of repeated exposures to the two floor types. Extinction sessions were conducted at the rate of two sessions per day for 7 days. As the Narp KO mice were not extinguishing, we continued for another nine sessions at the rate of one extinction session per day.

\section{Drugs}

Morphine was freshly prepared each day by dissolving morphine sulfate (National Institute on Drug Abuse, NIH) into sterile $0.9 \%$ saline. Injections were administered i.p. in volumes of $3 \mathrm{ml} / \mathrm{kg}$ for each mouse.

\section{RESULTS}

\section{Experiment 1: Morphine Psychomotor Sensitization}

Pretreatment phase. Figure 1 shows the locomotor response to repeated pretreatment injections of saline or morphine.Panels (a-d) show the time course (in 5 min bins) of the locomotor response to the first and last (seventh) pretreatment injection of saline ( $a$ and $b$ ) or morphine (c and d) for WT (left) and Narp KO (right) mice. Analysis of locomotor activity levels during the preinjection habituation periods (Figure 1a-d, areas left of the stippled lines) showed that in both WT and KO mice placement into the activity chambers alone produced a spontaneous locomotor response that quickly dissipated during the $30 \mathrm{~min}$ habituation period (Fs $>20.1, p s<0.001$, for effect of time). In addition, except for WT mice that received repeated injections of saline (panel a), the locomotor response seen after placement in the test environment was attenuated on the seventh session compared to the first test session (Fs $>7.2, p<0.05$, for effects of session); no interaction effects of session $\times$ time were found.

Injections of saline produced a similar, small increase in locomotor activity in WT and KO mice (panels a and b, areas to the right of the stippled lines) followed by a gradual decline in activity during the $120 \mathrm{~min}$ test session. No 
a
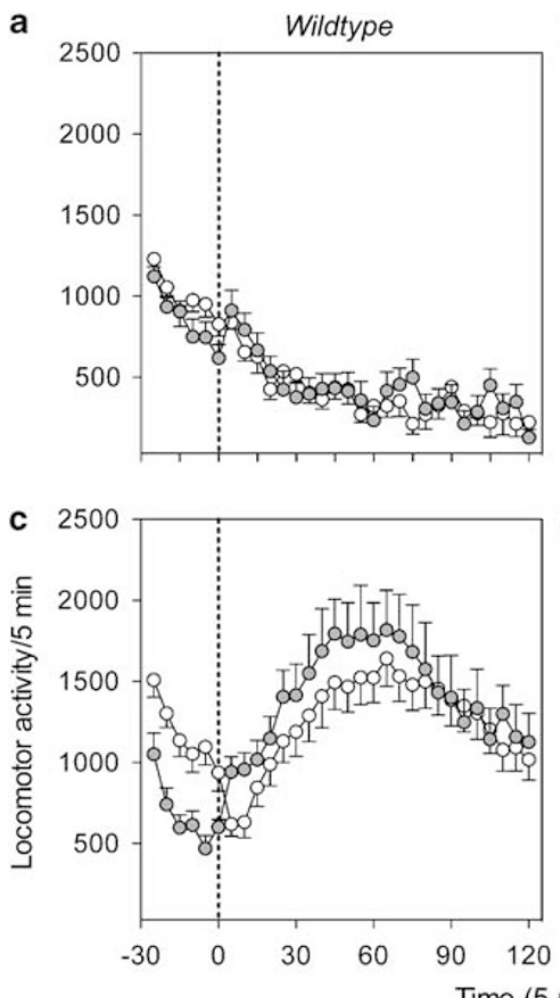

b

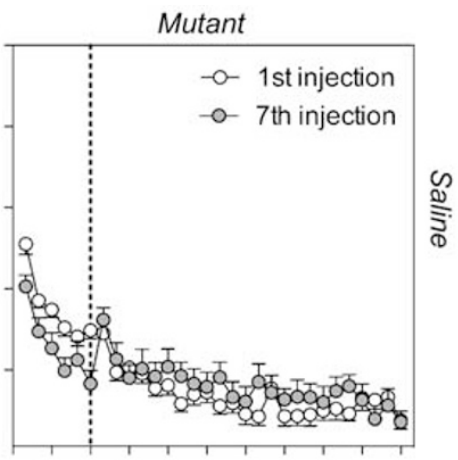

d

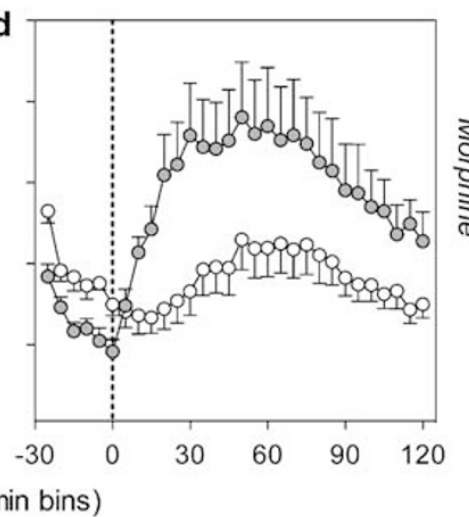

e

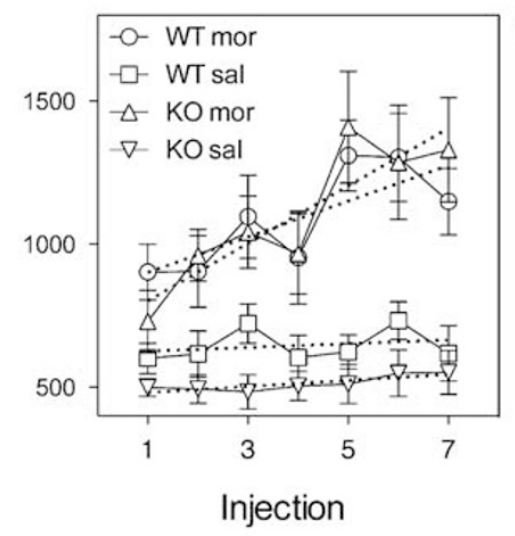

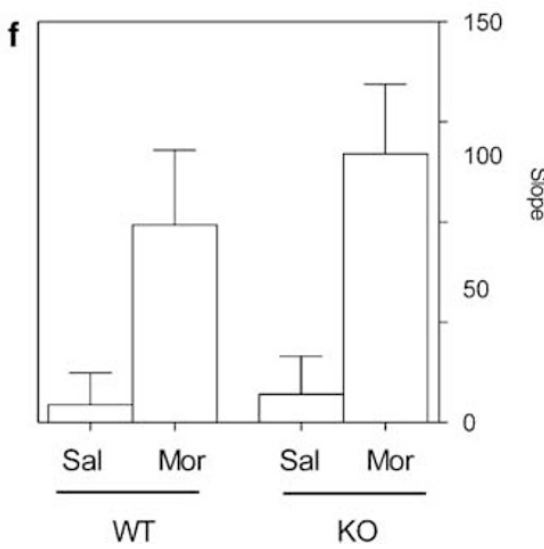

Figure I Locomotor responses during morphine pretreatment phase. Average number of horizontal activity counts in 5 min bins across the 30 min preinjection habituation period (area left of stippled line) and the $120 \mathrm{~min}$ postinjection period following the first and seventh injection of saline (a, b) or $10 \mathrm{mg} / \mathrm{kg}$ morphine (c, d) in Narp wild-type (WT; a, c) or knockout (KO; b, d) mice. Panel (e) shows the average number of locomotor activity counts per 5 min during the 30 min postinjection period across 7 saline or morphine treatment days in WT and KO mice. Panel (f) shows the slope coefficients of best-fit linear regression curves for WT and $\mathrm{KO}$ mice receiving morphine or saline injections across seven treatment sessions. The error bars indicate SEM.

change in the locomotor response to saline was seen as a function of treatment injections in either WT or KO mice. Two-way ANOVA resulted in significant effects of time (Fs $>7.8, p s<0.0001$ ), but no significant effects of session or time $\times$ session interaction.

Similar analysis was conducted on the time course of the locomotor responses to repeated injections of morphine in WT and Narp KO mice (panels $\mathrm{c}$ and d, areas right of the stippled lines). In both WT and KO mice, morphine administration produced an immediate and pronounced increase in locomotor activity that peaked around $60 \mathrm{~min}$ after the injection and then gradually declined during the second half of the treatment session. Interestingly, comparison of the time course data for WT and KO mice revealed a much smaller treatment-related effect on morphine responsiveness in WT mice (see below) than in KO mice. Indeed, two-way ANOVAs conducted on the locomotor response over the entire 120 min test session yielded a significant effect of time in WT mice $(\mathrm{F}(23,16)>9.9, p<0.0001)$, but no effects of session or session $\times$ time interaction ( $\mathrm{Fs}<0.7$, $p s>0.45)$. By contrast, in Narp KO mice, we observed significant effects of time $(\mathrm{F}(23,18)=9.9, p<0.01)$, session $(\mathrm{F}(1,18)=4.9, p<0.05)$, as well as a time $\times$ session interaction $(\mathrm{F}(23,18)=2.1, p<0.01)$. This genotype difference was principally due to a much smaller locomotor response to the first injection of morphine in Narp KO mice. Thus, 
analysis of the response of WT $v s \mathrm{KO}$ mice to the first morphine injection yielded a significant effect of time $(\mathrm{F}(23,17)=16.7, p<0.0001)$ and a significant interaction between time and genotype $(\mathrm{F}(23,17)=2.2, p<0.01)$.

The pretreatment phase data were next analyzed for differences as a function of pretreatment and genotype occurring during the first $30 \mathrm{~min}$ following the injection of saline or morphine. Thus, panel (e) shows the locomotor response (per $5 \mathrm{~min}$ bin) during the first $30 \mathrm{~min}$ following the injection of saline or morphine across the 7-day pretreatment phase. These data were analyzed for changes in locomotor responses across test sessions as a function of pretreatment or genotype using linear regression analysis. In this model, sensitization is indicated by a significant positive slope (relative to 0 ) in the linear curve fitted to the locomotor responsiveness results as a function of pretreatment session (ie, injection). Figure if shows the calculated slope coefficients for individual mice as a function of genotype and pretreatment drug. In both WT and Narp KO mice, repeated morphine treatments resulted in a significant increase in locomotor activity across test sessions (WT, slope $=62.5 \pm 25.1, \quad \mathrm{~F}(1,61)=6.2, \quad p<0.05 ; \quad \mathrm{KO}, \quad$ slope $=$ $100.5 \pm 25.8, \mathrm{~F}(1,69)=12.2, p<0.001)$. By contrast, repeated injections of saline did not produce a significant change in locomotor responsiveness in either genotype ( $p s>0.35)$. In addition, direct comparison of slopes as a function of pretreatment and genotype yielded a significant effect of pretreatment $(\mathrm{F}(1,35)=11.2 ; p<0.001)$, but no significant main or interaction effect of genotype $(p s>0.34)$. In summary, both WT and Narp KO mice showed evidence of behavioral sensitization as indicated by a progressive change across sessions in the locomotor responsiveness to injections of morphine during the first 30 min postinjection period. Importantly, no differences in sensitization as a function of genotype were seen.

Challenge tests. Following a 7-day posttreatment withdrawal period, saline- and morphine-treated mice received four challenge injections to assess their response to injections of vehicle and three increasing doses of morphine (3, 10, and $30 \mathrm{mg} / \mathrm{kg}$, respectively; one injection per day). Figure 2 shows the time courses (in $5 \mathrm{~min}$ bins) of the locomotor response to these challenge injections for WT (left panels) and Narp KO (right panels) mice. As found previously, mere placement into the testing chambers produced an increase in spontaneous locomotor activity that progressively dissipated during the $1-\mathrm{h}$ preinjection habituation period. Although there were no large and consistent differences in locomotor response during the preinjection habituation period as a function of genotype or pretreatment, some variation was evident and resulted in differences between groups' baseline response levels at the time of injection. For this reason, dose-effect curves to assess differences in locomotor responses on the challenge test as a function of genotype and pretreatment (Figure 3) were calculated by subtracting locomotor activity levels at the time of injection (time 0 ) from the locomotor response following the challenge injections of vehicle or morphine.

In addition, inspection of the time course of locomotor responses following the challenge injections showed that for most challenge doses of morphine (and vehicle) differences in locomotor responses to morphine as a function of pretreatment in $\mathrm{WT}$ and $\mathrm{KO}$ mice occurred within the first 30 min postinjection (Figure 2; panels $b, d, e, f$, and $g$, but not $\mathrm{h}$ ). Therefore, to maximize the likelihood of detecting changes and assessing genotype differences in locomotor activation as a function of pretreatment, dose-effect curves were compiled by averaging the locomotor responses during the first $30 \mathrm{~min}$ of the test sessions only (Figure 3 ).

The dose-effect curves for WT (Figure 3a) and Narp KO (Figure 3b) mice indicated that both genotypes showed a robust response to increasing challenge doses of morphine and that prior exposure to morphine resulted in a greater response relative to saline pretreatment. A three-way ANOVA that included genotype, pretreatment, and dose as variables yielded a significant effect of dose $(\mathrm{F}(1,105)=$ 82.6, $p<0.0001)$, pretreatment $(\mathrm{F}(1,35)=18.9, p<0.0001)$, and the interaction of dose $\times$ pretreatment $(\mathrm{F}(3,105)=5.9$, $p<0.01$ ), but not significant main or interaction effects with genotype $(\mathrm{Fs}<1.0, p s>0.4)$. Follow-up two-way ANOVAs for each genotype separately revealed significant main effects of dose (Fs $>38.1$, ps $<0.0001$ ), pretreatment (Fs $>6.9, p s<0.05)$, and interaction effects of dose $\times$ pretreatment $(\mathrm{Fs}>6.9$, ps<0.05) for both WT and $\mathrm{KO}$ genotypes. A similar analysis failed to detect genotype differences in response to the challenge injections in either saline- or morphine-pretreated mice.

Finally, two-way ANOVA conducted on the locomotor response to a single challenge injection of $10 \mathrm{mg} / \mathrm{kg}$ morphine given 1 month following the last dose-effect test session (Supplementary Figure 2) revealed that morphinepretreated $\mathrm{WT}$ and $\mathrm{KO}$ mice had remained more sensitive to morphine $(\mathrm{F}(1,35)=5.3, p<0.05)$. In addition, $\mathrm{KO}$ mice also showed an overall decreased responsiveness to morphine $(\mathrm{F}(1,35)=5.4, p<0.05$, for main effect of genotype) but this effect did not depend on pretreatment history $(p=0.9$ for pretreatment $\times$ genotype $)$.

In summary, we found no apparent genotype differences in the locomotor response pattern to repeated pretreatment injections of morphine (or saline), to the challenge injections given after a 7-day withdrawal period, or to a longterm challenge injection of morphine given after a 1 month withdrawal period. Thus, both WT and Narp KO mice showed evidence of robust and comparable sensitization to the psychomotor-activating effects of morphine. However, Narp KO mice tended to show an overall hypoactive locomotor response to morphine, in particular to the first injection of morphine.

\section{Experiment 2: Morphine Place Preference Conditioning}

The results of the pre- and postconditioning preference tests for the morphine place conditioning experiment are shown in Figure 4 and these data are shown as the amount (in $\mathrm{min}$ ) and the percent of time spent on either the morphine- or saline-paired floors. As mentioned above, based on the preconditioning scores, mice within each genotype group were assigned such that the average preconditioning preference for each genotype on the (would-be) morphine-paired floor approximated 50\% (pairs of bars on the left of each panel).

Following the preconditioning preference test, all mice received eight conditioning sessions consisting of four 

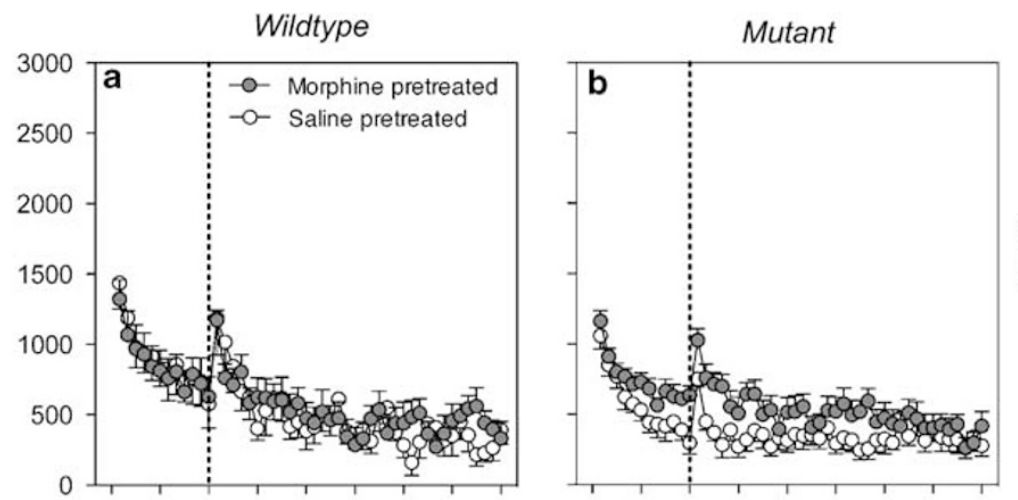

弯
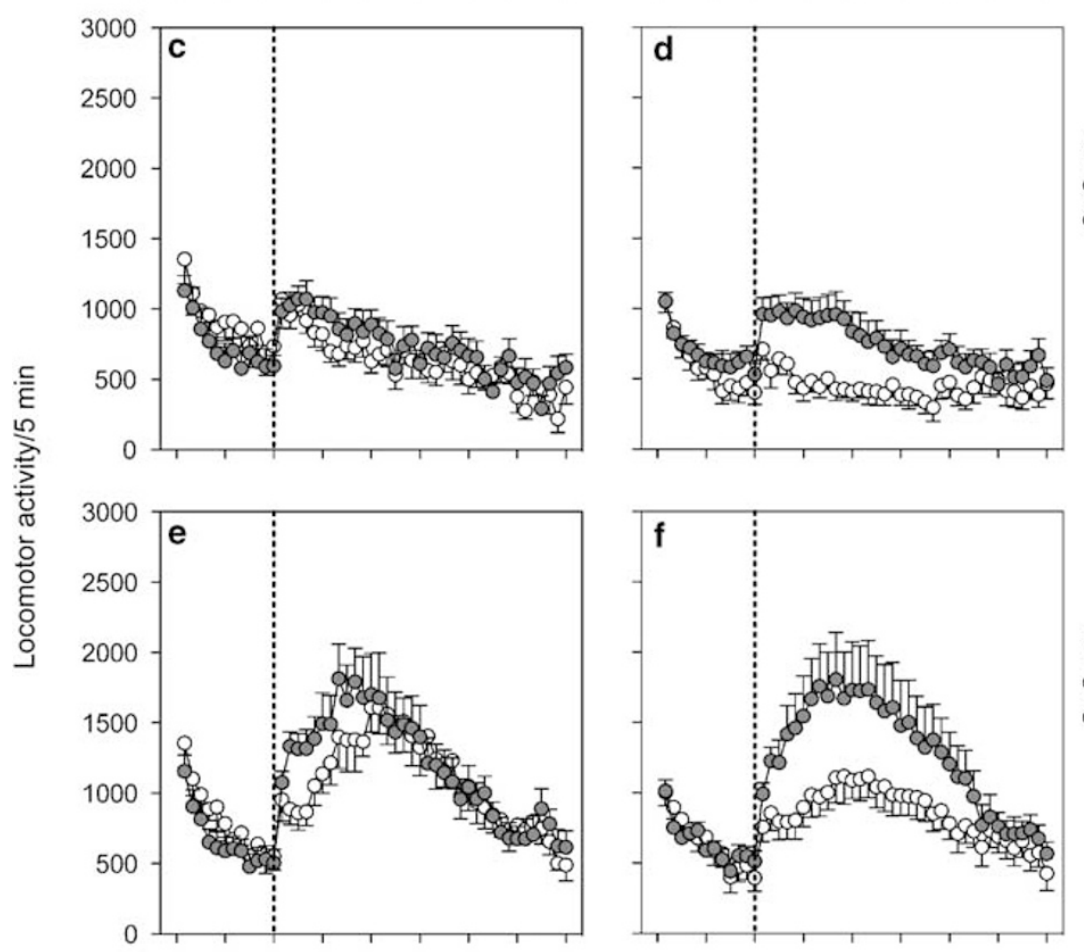

ผ
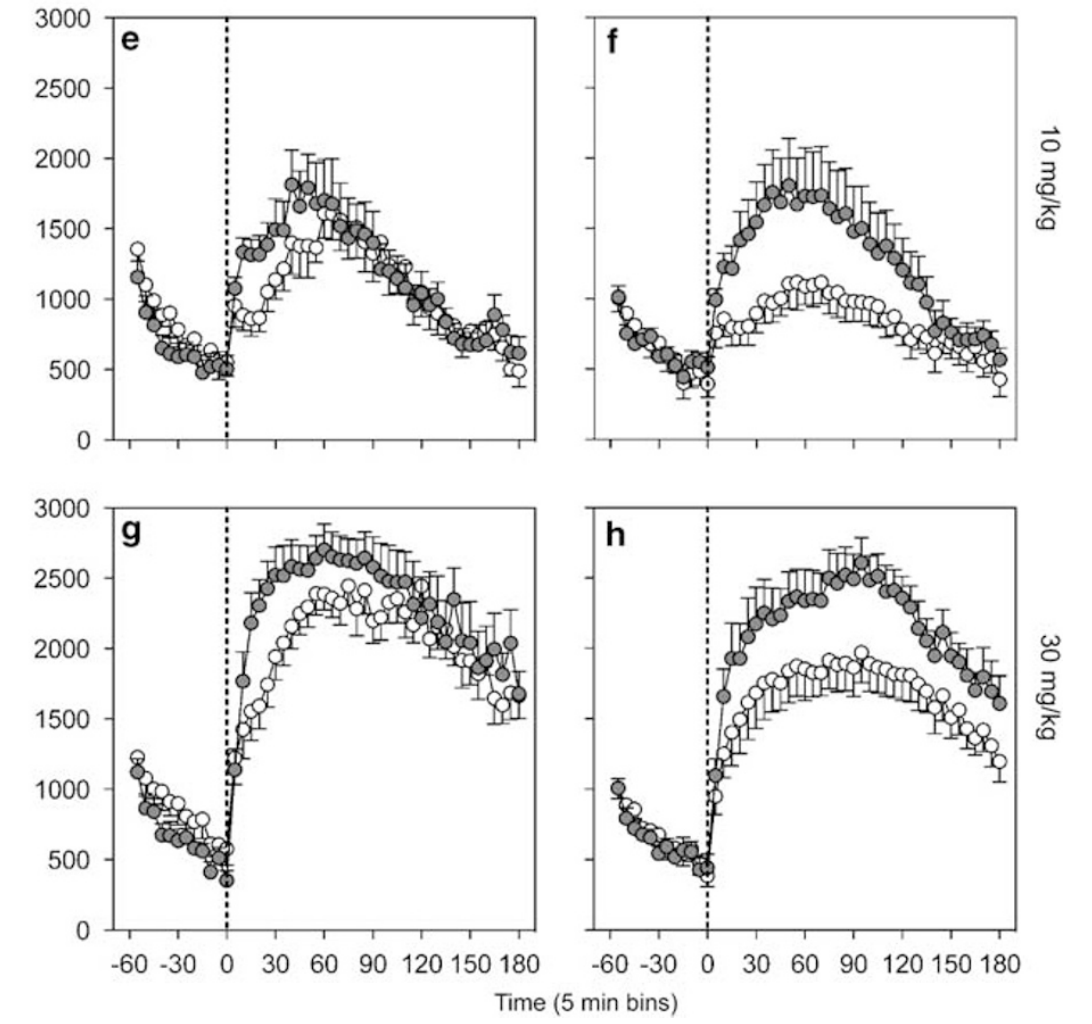

Figure 2 Locomotor response to challenge injections. The locomotor response to the challenge injections of saline or 3, 10 , or $30 \mathrm{mg} / \mathrm{kg}$ for wild-type (WT; panels a, c, e, and g, respectively) or Narp knockout (KO; panels b, d, f, and h, respectively) mice. Average number of horizontal activity counts in 5 min bins across the 60 min preinjection habituation period (area left of stippled line) and the 180 min postinjection period (area right of stippled line). The error bars indicate SEM.

injections of saline on one floor type (CS-) and four morphine injections on the alternate floor type $(\mathrm{CS}+)$ after which a postconditioning preference test was conducted
(Figure 4; right set of bars in each panel). In both WT and Narp KO mice, repeated pairing of morphine with one floor type produced a strong preference toward the 
a

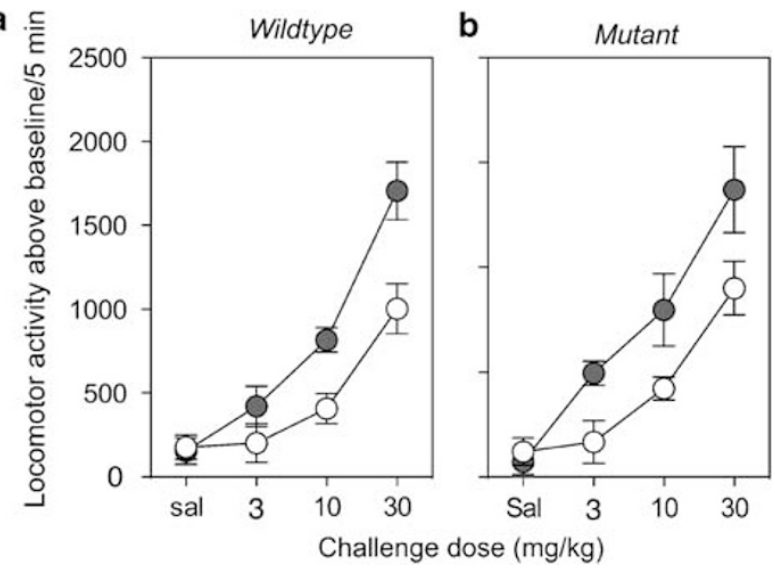

Figure 3 Dose-effect curves to challenge injections. The dose-effect curves for the first $30 \mathrm{~min}$ postinjection period to the challenge injections of saline and/or morphine for wild-type (WT; a) and Narp knockout (KO; b) mice pretreated with saline (open circles) or morphine (dark circles). Locomotor activity was expressed as a change from spontaneous activity level by subtracting activity levels at time 0 from the locomotor response per $5 \mathrm{~min}$ postinjection. The error bars indicate \pm SEM.

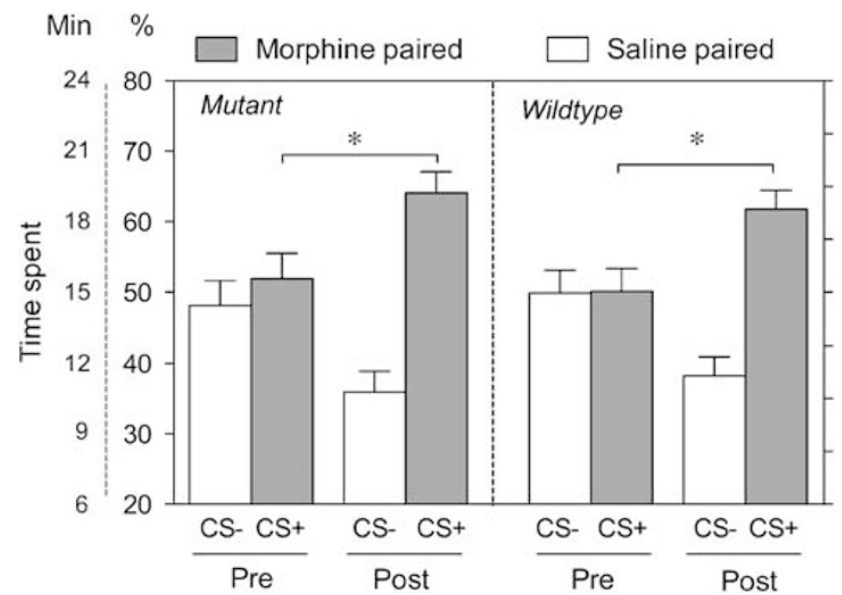

Figure 4 Development of morphine-induced conditioned place preference in wild-type (WT; left) and Narp knockout (KO; right) mice. WT and $\mathrm{KO}$ mice were assigned such that the time spent on the 'would-be' morphine- and saline-paired floors was approximately $50 \%$ during a 30 min preconditioning session. Following four injections of morphine paired with one floor and four injections of saline paired with the alternate floor, mice were tested on a single 30 min postconditioning preference test (postbias). The physical floor types that served as the morphine- or saline-paired floor were counterbalanced within each group. The error bars indicate \pm SEM. * $p<0.0001$

morphine-paired floor, relative to the saline-paired floor. Two-way ANOVA on the percentage of time spent on the morphine-paired floor yielded a significant effect of test (pre- $v s$ postconditioning; $\mathrm{F}(1,29)=23.78, p<0.0001$ ), but not of genotype $(\mathrm{F}(1,29)=0.1, p=0.97)$ or interaction between these factors $(\mathrm{F}(1,29)=0.6, p=0.45)$. These results indicate that morphine treatments produced a robust preference toward the morphine-paired stimulus in both WT and KO mice.

Following the first test for a postconditioning preference, an additional 23 daily test sessions were conducted to

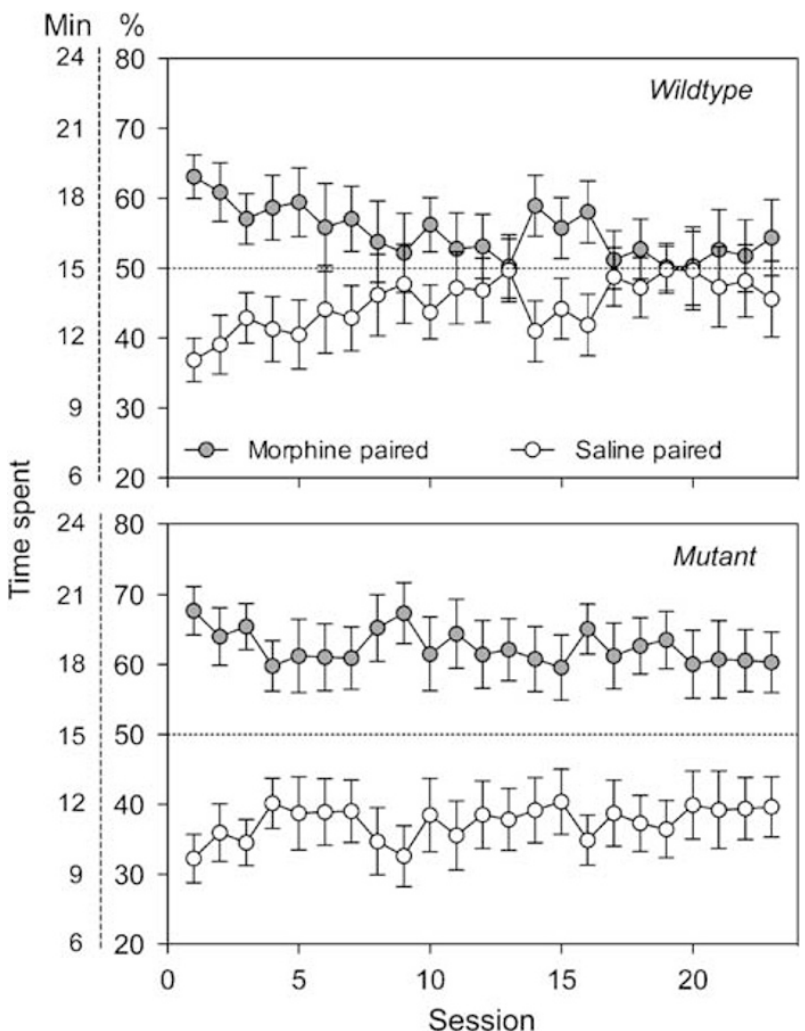

Figure 5 Effect of extinction on place preference. Average time spent on the previously morphine- and saline-paired floor types for wild-type (WT; top) and Narp knockout (KO) mice (bottom) across 23 (nonreinforced) extinction sessions (30 min each). The error bars indicate \pm SEM.

explore differences in the maintenance/extinction of the conditioned place preference. Figure 5 shows the percentage of time spent on the CS + and CS- floors across the 23 test sessions. Inspection of the data clearly reveals large differences in the rate of extinction between Narp WT and KO mice. That is, in WT mice we observed a progressive return to preconditioning levels within the first half of the extinction phase, consistent with the expectation that repeated exposure to the CS + and CS - in the absence of morphine resulted in extinction of the morphine place preference. By contrast, in Narp KO mice such an extinction curve was not seen and these mice failed to extinguish altogether. These data were analyzed in three different ways. First, as before, linear regression analysis was conducted for the time spent on the morphine-paired floor across sessions during the first half of the extinction phase (sessions 1-11). Next, slope coefficients for WT and KO mice were compared to determine differences from 0 (slopes different from 0 indicating a change in preference across sessions) and differences in slopes as a function of genotype (a greater slope indicating greater change in preference; Figure 6a). One sample $t$-test indicated that only WT mice, and not KO mice, showed a significant reduction in time spent on the $\mathrm{CS}+$ floor across session (mean slope $\mathrm{WT}=-1.173 ; t=2.8$, d.f. $=14, p<0.05$; mean slope $\mathrm{KO}=0.1447 ; t=0.3387$, d.f. $=15, p=0.7)$. In addition, the difference in slopes between WT and KO mice was significant $(t=2.215$, d.f. $=29$, $p<0.05)$ indicating that WT mice showed a greater change 

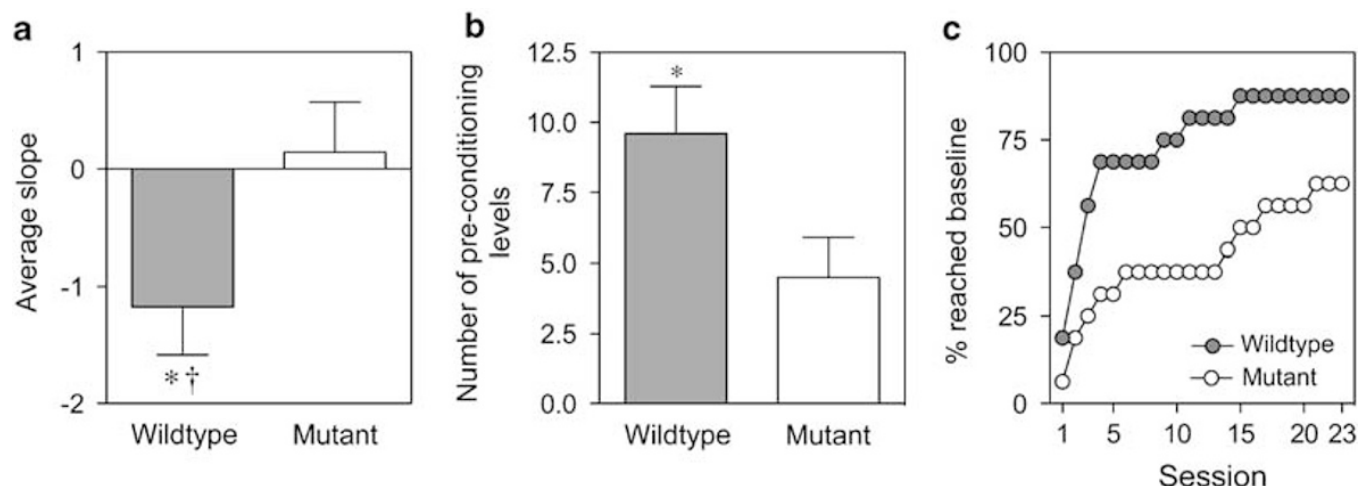

Figure 6 Three determinations of the difference in place preference extinction behavior in wild-type (WT) and Narp knockout (KO) mice. (a) The average slope across the first half of extinction training calculated for WT and Narp KO mice. (b) The total number of sessions mice in each group showed preconditioning level preference scores. (c) The results of the survival analysis to determine the rate at which mice reach preconditioning bias levels for each group. The error bars indicate \pm SEM. ${ }^{*} p<0.05,{ }^{\dagger} p<0.05$.

(decrease) in conditioned preference across sessions (ie, extinction) than $\mathrm{KO}$ mice.

The second way we analyzed the difference in extinction was to determine, for each mouse, the number of extinction sessions it showed a CS + preference level that was equal or less than the preconditioned level. This analysis is shown in Figure $6 \mathrm{~b}$ and demonstrates that across all 23 extinction sessions, more mice in the WT groups showed an absence of preference for the previously paired morphine floor relative to KO mice $(t=2.341$, d.f. $=29, p<0.05)$. Finally, a KaplanMeier survival analysis was conducted to compare the percentage of mice that reached extinction criterion (first extinction session during which mice spent equal or less time on CS + floor relative to the time spent during the preconditioning bias test) across the 23 extinction sessions. These data are shown in Figure $6 \mathrm{c}$ and the results show that WT mice showed both quicker (as indicated by a steeper curve) and more complete (indicated by a higher asymptote) extinction compared to KO mice. Statistical comparison showed that WT and KO groups were significantly different $\left(\chi^{2}=5.496, p<0.05\right)$.

In summary, the results of the conditioned place preference experiment show that Narp deletion does not significantly affect the ability of morphine to produce conditioned place preference. That is, following repeated morphine injections paired with placement into a distinct environment (floor type) Narp KO mice showed a preference comparable to WT mice for the morphinepaired floor. However, when we assessed the maintenance/ extinction of morphine place preference, by repeatedly exposing mice to the testing condition in the absence of morphine injection, we observed large differences between WT and KO mice. Specifically, as indicated by three different analyses of extinction performance, we found that whereas WT mice showed a gradual extinction of the morphine place preference, KO mice did not.

\section{DISCUSSION}

The view that defects in extinction may contribute to psychiatric abnormalities, such as anxiety disorders and relapse of drug-seeking behavior, has stimulated a resurgence of interest in understanding the behavioral and neurobiological mechanisms underlying extinction in a variety of experimental settings. A leading hypothesis is that extinction involves an active learning process by which conditioned responding is suppressed or inhibited. Accordingly, our findings could be interpreted as indicating that deletion of Narp interferes with inhibitory learning required for extinction to occur, but does not disrupt the initial acquisition of the conditioned association between an environmental cue and morphine treatment. It is particularly interesting, therefore, that we have recently found that Narp KO mice, while showing no deficits in performance on two (nondrug) appetitive learning tasks (conditioned reinforcement and Pavlovian instrumental transfer), showed a selective deficit in using sensory-specific information (flavor) to alter or suppress previously learned instrumental performance (sensory-selective devaluation; Johnson et al, 2007). Taken together these data suggest Narp KOs are deficient in their ability to update learned behavior when either the value of a reward (devaluation) or the predictive association between a Pavlovian stimulus and reward (conditioned place preference) changes.

As reviewed recently in Quirk and Mueller (2008), a number of brain regions have been implicated in extinction learning, including the hippocampus, infralimbic cortex (ventral medial PFC), and the basolateral amygdala - all of which show substantial Narp expression (Tsui et al, 1996; Lu et al, 2002; Reti et al, 2002b). Of course, in the present experiments, we used conventional Narp KOs that are globally deficient in Narp. Hence, future studies aimed at examining the impact of suppressing Narp expression selectively in these regions are likely to yield interesting new insights into the circuitry mediating extinction learning in this paradigm.

As Narp has been implicated in regulating AMPA receptor trafficking, it is noteworthy that Sutton et al (2003) detected changes in the levels of AMPA (GluR1 and GluR2/3) receptor subunits in NAc as a consequence of instrumental extinction experience from cocaine selfadministration and that viral-mediated overexpression of GluR1 and GluR2 receptors facilitates extinction learning following cocaine self-administration. Furthermore, withdrawal from chronic cocaine self-administration induces a 
decrease in Narp expression in the NAc shell and this decrease is reversed by extinction training (Self $e t$ al, 2004). Although these biochemical results were obtained in studies conducted on rats undergoing cocaine self-administration and our studies employed passive administration of morphine to mice, taken together these results suggest that Narp may be important in the alterations in GluR subunit expression observed in the NAc following drug withdrawal and extinction.

Our finding that Narp KO mice perform normally in the sensitization paradigm fits with a previous report exploring the relationship between Narp activity and sensitization to the psychomotor-activating effects of cocaine or amphetamine ( $\mathrm{Lu}$ et al, 2002). These investigators reported that behaviorally sensitizing treatment regimens of either amphetamine or cocaine did not alter Narp protein expression in VTA, PFC, or NAc - three key regions in the development and expression of psychomotor stimulant and opiate sensitization. The present results therefore appear consistent with and extend these earlier findings by demonstrating that Narp is not necessary for morphine sensitization.

Although sensitization was unimpaired in Narp KO mice, we did note significant differences in their locomotor activity during the first phase of the paradigm. In contrast to WT mice, Narp KO mice showed a more pronounced increase in psychomotor activation over the course of the pretreatment phase of the experiment. Of note, $\mathrm{Lu}$ et al (2002) also reported that in PFC but not in other regions such as the NAc or VTA, differences in Narp immunoreactivity were significantly correlated with individual differences in the response to a novel environment. Thus, rats that showed a greater spontaneous activity response following placement in a novel environment also showed greater constitutive Narp levels in PFC. Although in the present study we found no marked genotypic differences in the spontaneous locomotor response to placement in the novel environment (Figure 1, habituation period), Narp KO mice did show a hypoactive locomotor response to the first injection of morphine given during the pretreatment phase of the experiment. As the psychomotor response to morphine, as well as to psychomotor stimulant drugs such as amphetamine and cocaine, is often strongly dependent on the novelty of the environment in which the drug is administered (Badiani et al, 2000; Paolone et al, 2003; Ferguson et al, 2004), it is conceivable that the decreased responsiveness of Narp KO mice to morphine may be due to their decreased response to the novelty of the test environment, as opposed to a decreased sensitivity to morphine per se.

In summary, our behavioral analysis of the impact of morphine on Narp KO mice demonstrates that Narp plays a selective role in mediating extinction of place preference conditioning. These results suggest that further studies aimed at defining Narp's role in regulating AMPA receptor trafficking and at suppressing Narp expression selectively in individual limbic neuronal populations will advance our understanding of the neuronal circuitry and synaptic mechanisms that mediate extinction learning. Furthermore, as treatments that enhance extinction may be useful in treating drug abuse, these findings suggest that the Narp signaling pathway represents a potential therapeutic target.

\section{ACKNOWLEDGEMENTS}

This research work was funded by NIH grants RO1DA016303 and RR017688.

\section{DISCLOSURES/CONFLICTS OF INTEREST}

Dr Holland declares that over the past 3 years he has received compensation from Howard Hughes Medical Institute, Binghamton University, Columbia University, Yale University, University of Sao Paulo, University of Seville, and Emory University.

Other authors have nothing to disclose.

\section{REFERENCES}

Badiani A, Oates MM, Robinson TE (2000). Modulation of morphine sensitization in the rat by contextual stimuli. Psychopharmacology 151: 273-282.

Bjartmar L, Huberman AD, Ullian EM, Rentería RC, Liu X, Xu W et al (2006). Neuronal pentraxins mediate synaptic refinement in the developing visual system. J Neurosci 26: 6269-6281.

Carr D, Kalivas PW (2006). Orexin: a gatekeeper of addiction. Nat Med 12: 274-276.

Cho RW, Park J, Wolff SBE, Xu D, Hopf C, Kim J et al (2008). mGluR1/5-dependent long-term depression requires the regulated ectodomain cleavage of neuronal pentraxin NPR by TACE. Neuron 57: 858-871.

Cunningham CL (1995). Localization of genes influencing ethanolinduced conditioned place preference and locomotor activity in BXD recombinant inbred mice. Psychopharmacology 120: 28-41.

Cunningham CL, Niehus DR, Malott DH, Prather LK (1992). Genetic differences in the rewarding and activating effects of morphine and ethanol. Psychopharmacology 107: 385-393.

Ferguson SM, Thomas MJ, Robinson TE (2004). Morphineinduced c-fos mRNA expression in striatofugal circuits: modulation by dose, environmental context, and drug history. Neuropsychopharmacology 29: 1664-1674.

Fitzgerald LW, Ortiz J, Hamedani AG, Nestler EJ (1996). Drugs of abuse and stress increase the expression of GluR1 and NMDAR1 glutamate receptor subunits in the rat ventral tegmental area: common adaptations among cross-sensitizing agents. J Neurosci 16: 274-282.

Glass MJ, Kruzich PJ, Colago EE, Kreek MJ, Pickel VM (2005). Increased AMPA GluR1 receptor subunit labeling on the plasma membrane of dendrites in the basolateral amygdala of rats selfadministering morphine. Synapse 58: 1-12.

Glass MJ, Lane DA, Colago EE, Chan J, Schlussman SD, Zhou Y et al (2008). Chronic administration of morphine is associated with a decrease in surface AMPA GluR1 receptor subunit in dopamine D1 receptor expressing neurons in the shell and non-D1 receptor expressing neurons in the core of the rat nucleus accumbens. Exp Neurol 210: 750-761.

Hyman SE, Malenka RC, Nestler EJ (2006). Neural mechanisms of addiction: the role of reward-related learning and memory. Annu Rev Neurosci 29: 565-598.

Jacobs EH, Wardeh G, Smit AB, Schoffelmeer AN (2005). Morphine causes a delayed increase in glutamate receptor functioning in the nucleus accumbens core. Eur J Pharmacol 511: 27-30.

Johnson AW, Crombag HS, Takamiya K, Baraban JM, Holland PC, Huganir RL et al (2007). A selective role for neuronal activity regulated pentraxin in the processing of sensory-specific incentive value. J Neurosci 27: 13430-13435.

Kalivas PW, O'Brien C (2008). Drug addiction as a pathology of staged neuroplasticity. Neuropsychopharmacology 33: 166-180. 
Lu W, Marinelli M, Xu D, Worley PF, Wolf ME (2002). Amphetamine and cocaine do not increase Narp expression in rat ventral tegmental area, nucleus accumbens or prefrontal cortex, but Narp may contribute to individual differences in responding to a novel environment. Eur J Neurosci 15: 2027-2036.

Nestler EJ (2001). Molecular basis of long-term plasticity underlying addiction. Nat Rev Neurosci 2: 119-128.

O’Brien RJ, Xu D, Petralia RS, Steward O, Huganir RL, Worley P (1999). Synaptic clustering of AMPA receptors by the extracellular immediate-early gene product Narp. Neuron 23: 309-323.

Paolone G, Burdino R, Badiani A (2003). Dissociation in the modulatory effects of environmental novelty on the locomotor, analgesic, and eating response to acute and repeated morphine in the rat. Psychopharmacology 166: 146-155.

Quirk GJ, Mueller D (2008). Neural mechanisms of extinction learning and retrieval. Neuropsychopharmacology 33: 56-72.

Reti IM, Baraban JM (2003). Opiate withdrawal induces Narp in the extended amygdala. Neuropsychopharmacology 28: 1606-1613.

Reti IM, Reddy R, Worley PF, Baraban JM (2002a). Selective expression of Narp, a secreted neuronal pentraxin, in orexin neurons. J Neurochem 82: 1561-1565.

Reti IM, Reddy R, Worley PF, Baraban JM (2002b). Prominent Narp expression in projection pathways and terminal fields. J Neurochem 82: 935-944.
Robinson TE, Kolb B (1999). Morphine alters the structure of neurons in the nucleus accumbens and neocortex of rats. Synapse 33: 160-162.

Saal D, Dong Y, Bonci A, Malenka RC (2003). Drugs of abuse and stress trigger a common synaptic adaptation in dopamine neurons. Neuron 37: 577-582.

Self DW, Choi KH, Simmons D, Walker JR, Smagula CS (2004). Extinction training regulates neuroadaptive responses to withdrawal from chronic cocaine self-administration. Learn Mem 11: 648-657.

Sutton MA, Schmidt EF, Choi KH, Schad CA, Whisler K, Simmons D et al (2003). Extinction-induced upregulation in AMPA receptors reduces cocaine-seeking behaviour. Nature 421: 70-75.

Szumlinski KK, Kalivas PW, Worley PF (2006). Homer proteins: implications for neuropsychiatric disorders. Curr Opin Neurobiol 16: 251-257.

Tsui CC, Copeland NG, Gilbert DJ, Jenkins NA, Barnes C, Worley PF (1996). Narp, a novel member of the pentraxin family, promotes neurite outgrowth and is dynamically regulated by neuronal activity. J Neurosci 16: 2463-2478.

Vezina P, Stewart J (1987). Morphine conditioned place preference and locomotion: the effect of confinement during training. Psychopharmacology 93: 257-260.

Supplementary Information accompanies the paper on the Neuropsychopharmacology website (http://www.nature.com/npp) 